\title{
Research on the performance of recycled concrete powder self- leveling mortar based on orthogonal experiment
}

\author{
Yuezhong Lin ${ }^{1}$, Xingxing Zhang ${ }^{2}$ andYachao Wang ${ }^{3}$ \\ ${ }^{1,2,3}$ College of Civil Engineering and Architecture, Shandong University of Science and Technology, 266590, Qingdao, Shandong.
}

\begin{abstract}
Waste concrete in the construction waste is reprocessed into concrete sand and powder [1]. Recycled concrete sand with a particle size between 0.15 and $0.25 \mathrm{~mm}$ partially replaces natural sand, and the recycled concrete powder with a particle size less than $0.075 \mathrm{~mm}$ partially replaces cement. The five-factor four-level orthogonal experiment was used to study the replacement amount of recycled concrete powder, the replacement amount of recycled concrete sand, the amount of dispersible latex powder, the amount of polycarboxylate water-reducing agent, the ratio of bone cement, and the five factors on the fluidity of selfleveling mortar. The influence of the three performance indicators of bond tensile strength and dimensional change rate; through the range analysis of the above indicators. The analysis results show that the content of recycled concrete powder instead of cement has the greatest impact on the tensile bond strength and dimensional change rate of recycled concrete powder self-leveling mortar, and the content of Polycarboxylate Superplasticizer has the greatest influence on the fluidity.
\end{abstract}

\section{INTRODUCTION}

Construction waste refers to the solid waste generated during the construction and demolition of buildings (structures), mainly solid waste generated during the demolition of buildings, specifically including mortar, concrete, metal, concrete blocks, blocks and other buildings generated during the demolition of buildings Rubbish. How to use construction waste scientifically so that it can be a green renewable material has become a research focus $[2,3]$. In this paper, by exploring the recycling of recycled concrete into aggregate, it can effectively reduce construction waste and energy consumption. Green building materials such as recycled concrete powder formed after crushing, grinding, and screening of waste concrete make concrete a renewable energy source $[4,5]$.

In this paper, the waste concrete blocks are crushed and ground into recycled concrete powders of different fineness to partially replace cement and sand, doublemixed and double-generation, and combined with water reducer, cellulose [6] ether, latex powder and defoamer the cement-based self-leveling mortar is prepared by optimizing the mix ratio. On the basis of retaining its original fluidity, rapid hardening, durability and abrasion resistance, it fully uses the substitution of waste concrete powder and effectively improves the resource utilization of construction waste rate.

\section{EXPERIMENTAL RAW MATERIALS}

In this experiment, the process of crushing, grinding and processing waste concrete blocks into recycled concrete powder is carried out under natural conditions, and the particle size is between 0.25 Concrete powder between $\mathrm{mm}$ and $0.15 \mathrm{~mm}$ is used as concrete sand instead of natural sand. In the screening, the concrete sand with a particle size of less than $0.15 \mathrm{~mm}$ is deeply ground with a ball mill and then sieved again, and concrete powder with a particle size of less than $0.075 \mathrm{~mm}$ is taken as the fine concrete powder instead of cement. As showing in Figure 1 .

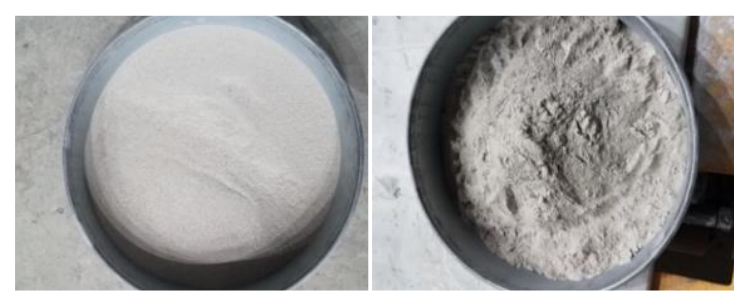

Figure 1 Recycled concrete sand and powder

\section{EXPERIMENTS}

\subsection{Experimental benchmark mix ratio}

This test adopts the ordinary Portland cement-aluminate cement binary system, mainly ordinary Portland cement. The performance of self-leveling mortar is tested by changing the mixing amount of aluminate cement [7]. Comprehensive analysis of the performance indicators of strength and compressive strength, the ratio of aluminate cement to ordinary Portland cement settles in 1:8.

The content of cellulose ether has a significant impact on the fluidity of the mortar. Depending on the experiment,

\footnotetext{
* Corresponding author: 15588285580@163.com
} 
the equivalent content is $0.01 \%$. The initial fluidity of the mortar is $15.3 \mathrm{~cm}$ and the fluidity of $20 \mathrm{~min}$ is $15.2 \mathrm{~cm}$, which meets the experimental requirements.

The bubbles on the surface of the self-leveling mortar decrease with the increase of the amount of defoamer, but the excessive amount of defoamer will cause the surface of the self-leveling mortar to produce black gloss. The final dosage of the defoamer is setting at $0.3 \%$ in this experiment.

Water glue ratio: When the water glue ratio is 0.40 , the initial fluidity is $151 \mathrm{~mm}$, the $20 \mathrm{~min}$ fluidity is $142 \mathrm{~mm}$, $24 \mathrm{~h}$ compressive strength is $8.2 \mathrm{MPa}$, and the $24 \mathrm{~h}$ flexural strength is $3.8 \mathrm{MPa}$.

\subsection{Orthogonal experiment scheme}

The study of the self-leveling mortar of waste concrete powder in this test includes three performance indicators of fluidity, bonding strength, and dimensional change rate. The test factor $\mathrm{A}$ is the mixing of coarse concrete powder with a particle size between $0.25 \mathrm{~mm}$ and $0.15 \mathrm{~mm}$ instead of sand. Factor B is the amount of fine concrete powder with a particle size of less than $0.075 \mathrm{~mm}$ instead of cement, factor $\mathrm{C}$ is redispersible latex powder, factor $\mathrm{D}$ is Polycarboxylate Superplasticizer [8], factor E is bone cement ratio, level factors are shown in the table 1 . Orthogonal test table 2 adopts $L_{16}\left(4^{5}\right)$ combination.

Table 1 Factors and levels of orthogonal test

\begin{tabular}{clllll}
\hline Level factor & $\mathrm{A}$ & $\mathrm{B}$ & $\mathrm{C}$ & $\mathrm{D}$ & $\mathrm{E}$ \\
\hline 1 & $5 \%$ & $5 \%$ & $0.9 \%$ & $0.45 \%$ & 1.0 \\
2 & $10 \%$ & $10 \%$ & $1.2 \%$ & $0.55 \%$ & 1.1 \\
3 & $15 \%$ & $15 \%$ & $1.5 \%$ & $0.65 \%$ & 1.2 \\
4 & $20 \%$ & $20 \%$ & $1.8 \%$ & $0.75 \%$ & 1.3 \\
\hline
\end{tabular}

\subsection{Range analysis}

\subsubsection{Flow range analysis}

The optimal combination of the initial fluidity of the recycled concrete powder self-leveling mortar is $\mathrm{A}_{2} \mathrm{~B}_{1} \mathrm{C}_{2} \mathrm{D}_{2} \mathrm{E}_{3}$. It can be judged that the Polycarboxylate Superplasticizer has the greatest impact on the fluidity.

Table 2 Scheme and results of orthogonal experiment $L_{16}\left(4^{5}\right)$

\begin{tabular}{cccccccccc}
\hline Sample & A & B & C & D & E & Bond tensile strength (MPa) & Size change rate $(\%)$ & Liquidity $(\mathrm{mm})$ \\
\hline \multicolumn{1}{c}{} & \multicolumn{1}{c}{ ( } & \multicolumn{1}{c}{ Initial } & $20 \mathrm{~min}$ \\
\hline 1 & 1 & 1 & 1 & 1 & 1 & 1.4 & 0.15 & 149 & 142 \\
2 & 1 & 2 & 2 & 2 & 2 & 1.5 & 0.13 & 157 & 144 \\
3 & 1 & 3 & 3 & 3 & 3 & 1.7 & 0.11 & 128 & 120 \\
4 & 1 & 4 & 4 & 4 & 4 & 1.9 & 0.11 & 156 & 143 \\
5 & 2 & 1 & 2 & 3 & 4 & 1.3 & 0.12 & 151 & 133 \\
6 & 2 & 2 & 1 & 4 & 3 & 1.2 & 0.14 & 157 & 148 \\
7 & 2 & 3 & 4 & 1 & 2 & 1.6 & 0.08 & 151 & 139 \\
8 & 2 & 4 & 3 & 2 & 1 & 1.5 & 0.09 & 152 & 142 \\
9 & 3 & 1 & 3 & 4 & 2 & 1.2 & 0.07 & 150 & 141 \\
10 & 3 & 2 & 4 & 3 & 1 & 1.3 & 0.06 & 116 & 109 \\
11 & 3 & 3 & 1 & 2 & 4 & 0.9 & 0.06 & 158 & 152 \\
12 & 3 & 4 & 2 & 1 & 3 & 1.1 & 0.08 & 160 & 151 \\
13 & 4 & 1 & 4 & 2 & 3 & 1.1 & 0.03 & 155 & 147 \\
14 & 4 & 2 & 3 & 1 & 4 & 0.9 & 0.05 & 132 & 126 \\
15 & 4 & 3 & 2 & 4 & 1 & 0.8 & 0.05 & 125 & 117 \\
16 & 4 & 4 & 1 & 3 & 2 & 0.7 & 0.04 & 122 & 116 \\
\hline
\end{tabular}

Table 3 Analysis of the flow range table

\begin{tabular}{clllll}
\hline Factor & $\mathrm{A}$ & $\mathrm{B}$ & $\mathrm{C}$ & $\mathrm{D}$ & $\mathrm{E}$ \\
\hline$X_{1}$ & 590 & 606 & 586 & 592 & 542 \\
$X_{2}$ & 611 & 562 & 593 & 623 & 580 \\
$X_{3}$ & 584 & 562 & 562 & 518 & 600 \\
$X_{4}$ & 534 & 590 & 578 & 588 & 597 \\
$\frac{X_{1}}{X_{2}}$ & 147.5 & 151.5 & 146.5 & 148 & 135.5 \\
$\frac{X_{3}}{X_{4}}$ & 152.8 & 140.5 & 148.2 & 155.8 & 145 \\
$R$ & 133.5 & 140.5 & 140.5 & 129.5 & 150 \\
$R$ & 19.3 & 11 & 144.5 & 147 & 149.3 \\
\hline
\end{tabular}

\subsubsection{Dimensional change rates range analysis}

The size change rate of the self-leveling mortar is a direct result of the cracking of the mortar. The smaller the value, the more beneficial the flow performance of the selfleveling mortar. The optimal combination of size changes rate of recycled concrete powder self-leveling mortar is $\mathrm{A}_{4} \mathrm{~B}_{3} \mathrm{C}_{4} \mathrm{D}_{2} \mathrm{E}_{2}$. The order of the $\mathrm{R}$ value determines that the mixing amount of concrete powder instead of cement has the greatest influence.

\begin{tabular}{cccccc}
\multicolumn{6}{c}{ Table 4 Dimensional change rates range analysis table } \\
\hline Factor & $\mathrm{A}$ & $\mathrm{B}$ & $\mathrm{C}$ & $\mathrm{D}$ & $\mathrm{E}$ \\
\hline$X_{1}$ & 0.5 & 0.37 & 0.39 & 0.36 & 0.35 \\
$X_{2}$ & 0.43 & 0.38 & 0.38 & 0.31 & 0.32 \\
$X_{3}$ & 0.27 & 0.3 & 0.32 & 0.33 & 0.36 \\
$X_{4}$ & 0.17 & 0.32 & 0.28 & 0.37 & 0.34 \\
$\overline{X_{1}}$ & 0.125 & 0.093 & 0.098 & 0.09 & 0.088 \\
$\overline{X_{2}}$ & 0.108 & 0.095 & 0.095 & 0.078 & 0.08 \\
$\overline{X_{3}}$ & 0.068 & 0.075 & 0.08 & 0.083 & 0.09 \\
$\overline{X_{4}}$ & 0.043 & 0.08 & 0.07 & 0.093 & 0.085 \\
$R$ & 0.082 & 0.02 & 0.028 & 0.015 & 0.01 \\
\hline
\end{tabular}

\subsubsection{Analysis of extremely poor bond strength}

The extreme difference analysis of the adhesive tensile strength of recycled concrete self-leveling mortar is shown in Table 5. it can be seen that the excellent combination of adhesive tensile strength of recycled concrete powder self-leveling mortar is $\mathrm{A}_{1} \mathrm{~B}_{4} \mathrm{C}_{4} \mathrm{D}_{4} \mathrm{E}_{3}$, the dosage of concrete powder instead of cement has the 
greatest influence.

Table 5 Analysis of extremely poor bond strength table

\begin{tabular}{clllll}
\hline Factor & $\mathrm{A}$ & $\mathrm{B}$ & $\mathrm{C}$ & $\mathrm{D}$ & $\mathrm{E}$ \\
\hline$X_{1}$ & 6.5 & 5 & 4.2 & 5 & 5 \\
$X_{2}$ & 5.6 & 4.9 & 4.7 & 5 & 5 \\
$X_{3}$ & 4.5 & 5 & 5.3 & 5 & 5.1 \\
$X_{4}$ & 3.5 & 5.2 & 5.9 & 5.1 & 5 \\
$\overline{X_{1}}$ & 1.63 & 1.25 & 1.05 & 1.25 & 1.25 \\
$\overline{X_{2}}$ & 1.4 & 1.23 & 1.18 & 1.25 & 1.25 \\
$\overline{X_{3}}$ & 1.13 & 1.25 & 1.33 & 1.25 & 1.28 \\
$\overline{X_{4}}$ & 0.88 & 1.3 & 1.48 & 1.28 & 1.25 \\
$R$ & 0.75 & 0.07 & 0.43 & 0.03 & 0.03 \\
\hline
\end{tabular}

\subsection{Mixing ratio optimization and performance test results}

The analysis results show that the content of recycled concrete powder instead of cement has the greatest impact on the tensile bond strength and dimensional change rate of recycled concrete powder self-leveling mortar, and the content of Polycarboxylate Superplasticizer has the greatest influence on fluidity. Therefore, $A_{2}$ is selected as the optimal level of factor $\mathrm{A}$; concrete powder is used as aggregate for self-leveling with less influence on various properties of mortar and material consumption. It can be inferred that $\mathrm{B}_{4}$ is the optimal level of factor $\mathrm{B}$.

\section{CONCLUSION}

1. According to the range analysis, the biggest factor that affects self-leveling mortar of recycled concrete is the content of concrete powder instead of cement, followed by the degree of influence of Polycarboxylate Superplasticizer.

2. The optimal mixing ratio of recycled concrete powder self-leveling mortar is $10 \%$ recycled concrete powder instead of cement, $20 \%$ recycled concrete sand instead of sand, and $1.8 \%$ of the cementitious material is the amount of redispersible latex powder. , the blending amount of Polycarboxylate Superplasticizer which accounts for $0.55 \%$ of the cementing material, the boneto-glue ratio is $1.2: 1$. The properties of the self-leveling recycled concrete mortar with the best mix ratio meet the requirements of the "Standard for Basic Performance Test Method of Building Mortar" (JGJ/T-2009) [9].

\section{References}

1. Chaojie Yi; Xiaodong $\mathrm{Li}$ and Hanbing $\mathrm{Xu}$; The Recovery and Utilization of Construction Waste: Waste Concrete,ICCREM 2013,Construction and Operation in the Context of Sustainability.2013

2. Ishtiyaq Gull; Testing of Strength of Recycled Waste Concrete and Its Applicability, Construction Engineering and Management Vol. 137, Issue 1 (January 2011)

3. A. M. Knaack; andY. C. Kurama;Design of Normal Strength Concrete Mixtures with Recycled Concrete Aggregates, Structures Congress 2011.

4. J. H. Zhou; H. J. He; X. H. Meng; and S. Huan,
Experimental Study of Recycled Concrete Columns under Large Eccentric Compression,Earth and Space 2010.

5. A. R. Gabr; and D. A. Cameron ;Properties of Recycled Concrete Aggregate for Unbound Pavement Construction, Journal of Materials in Civil Engineering,Vol. 24, Issue 6 (June 2012)

6. Hisseine; Ahmed F. Omran; and Arezki TagnitHamou; Influence of Cellulose Filaments on Cement Paste and Concrete. Journal of Materials in Civil Engineering; Vol30, Issue 6 (June 2018)

7. Huo Liqiang. Study on the influence of high alumina cement on the performance of cement-based selfleveling mortar[J].Construction Technology,2013,42(04):61-63.

8. Kazuo Yamada, Tomo Takahashi, Shunsuke Hanehara, Makoto Matsuhisa.Effects of the chemical structure on the properties of polycarbosylate-type superplasticizer[J]. Cement and Concrete Research,2000 30:197- 207.

9. National Standard of the People's Republic of China, "Standard for Basic Performance Test Method of Building Mortar"(JGJ/T-2009), Beijing, China Construction Industry Press, 2009. 